\title{
The Effect of Flow Velocity on Bridge Pillar Concrete Wings Using iRIC Software Nays2HD 3.0.
}

\author{
Nenny", Fenti Daud S., Sukmasari Antaria, Hamzah Al Imran \\ Department of Civil Irrigation, Faculty of Engineering, University of Muhammadiyah Makassar, Indonesia
}

Received October 21, 2021; Revised January 20, 2022; Accepted February 8, 2022

\section{Cite This Paper in the following Citation Styles}

(a): [1] Nenny, Fenti Daud S., Sukmasari Antaria, Hamzah Al Imran, "The Effect of Flow Velocity on Bridge Pillar Concrete Wings Using iRIC Software Nays2HD 3.0.," Civil Engineering and Architecture, Vol. 10, No. 2, pp. 620-631, 2022. DOI: 10.13189/cea.2022.100218.

(b): Nenny, Fenti Daud S., Sukmasari Antaria, Hamzah Al Imran (2022). The Effect of Flow Velocity on Bridge Pillar Concrete Wings Using iRIC Software Nays2HD 3.0.. Civil Engineering and Architecture, 10(2), 620-631. DOI: 10.13189/cea.2022.100218.

Copyright $(2022$ by authors, all rights reserved. Authors agree that this article remains permanently open access under the terms of the Creative Commons Attribution License 4.0 International License

\begin{abstract}
This experimental study discusses flow velocity around concrete wings for the reduction of scouring on bridge pillars. Therefore, this study aims to analyze the flow velocity around the bridge piers before and after the concrete flange curtain by using iRIC (International River Interface Cooperative) software Nays2HD 3.0. A soil channel model with trapezoidal cross-section, cylindrical pillar and concrete wing curtain model was used in this study. The observation objects were flow discharge (Q), flow velocity (v), flow depth (h), and scour depth elevation (ds) in each time interval. Furthermore, the simulation results showed that the lowest and the highest flow velocity were $0.000 \mathrm{~m} / \mathrm{s}$ and $0.998 \mathrm{~m} / \mathrm{s}$, respectively. The flow velocity that occurred around the bridge piers and concrete wings was relatively small due to the changing direction of flow after the concrete wings. Meanwhile, the scour that occurred around the bridge pillars was relatively small due to the presence of concrete wings in front of the pillars. Based on the validation results between the analysis of the iRIC software, Nays2DH 3.0 and a physical model at the output velocity (ms-1), there was an insignificant difference of $4.61 \%$.
\end{abstract}

Keywords Pillar, Curtain, Scour, Velocity, iRIC: Nays2DH 3.0.

\section{Introduction}

In most cases, the collapse of a bridge is due to unstable bridge piers used for load transfer. Common bridge problems across rivers are due to the failure of bridge structures, including foundations, pillars, and bridge abutments for support. The collapse of a bridge breaks the sub-bridge structure due to an extreme river flow, particularly the phenomenon of riverbeds around the bridge's foundations and pillars. Meanwhile, the main failure factor for the sub-bridge structure is the occurrence of riverbed subsidence (degradation) and local scour around the bridge pier foundation [1]. Erosion due to water flow blocked by the pillar alters the flow pattern and forms a vortex with deeper erosion and crashing pillars. These pillars are then carried away by the flow of the river which leads to the bridge falling apart (collapse). Furthermore, the effectiveness of scouring reduction using concrete wing curtains is based on the recommendation of the previous studies [2],[3].

The phenomenon of scouring on bridge pillars is the main cause of bridge damage and collapse. Scour depth prediction is influenced by several variables, including flow velocity, flow rate and bottom changes involving aggradation and degradation [4]. Subsequently, during bridge design, the scour is adjusted to the peak discharge associated with sediment transport at the bottom for the duration required to achieve scour balance [5].

In designing a scour bridge, the resulting scour is adjusted to several studies related to the flow velocity around the bridge pillars were carried out. Some examples include, the effect of flow velocity on local scouring around hexagonal pillars (laboratory model test) [2],[1], local scour analysis study for hexagonal pillar using 
rectangular curtain shape with wedge-shaped curve, and the model of protective pillar scouring using concave-sided curtain [1],[7].

Based on the studies above, the concrete wing curtain model was used on bridge pillars by observing the flow velocity before and after the wing curtain, on the pillars. This was carried out through the examination of the flow pattern conditions and the basic elevation, by considering the concrete wing curtain model placement after reducing scour around the bridge piers [5]. Therefore, this study aims to analyze the flow velocity effect of concrete wing curtains on bridge pillars using the iRIC software, Nays2HD 3.0. (Dr. Yasuyuki Shimizu dan Hiroshi Takebayashi)[8].

\section{Materials and Methods}

The method used in this study was laboratory experimentation and literature review. The types of tests carried out were basic materials and flow tests to determine the type of flow and flow rate. Furthermore, these tests were carried out at the Soil Mechanics and river Laboratory, Faculty of Engineering, University of Muhammadiyah Makassar [3].

\subsection{Chanel Model}

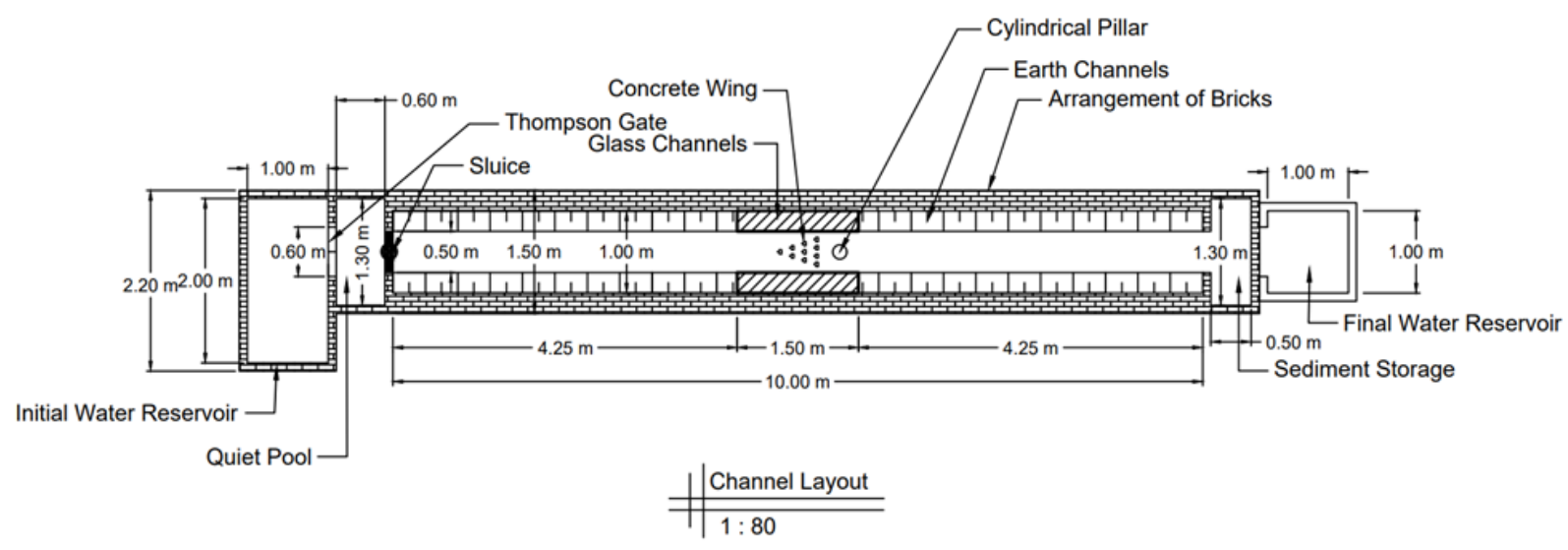

Figure 1. Open channel model with trapezoidal cross section This sudy used pillar model obtained from concrete blocks shaped according to the model. Furthermore, it is a cylindrical pillar model with a height and diameter of $40.0 \mathrm{~cm}$ and $10 \mathrm{~cm}$ respectively. The model was placed at the channel center with a distance of $6.0 \mathrm{~m}$ upstream [5],[9]. The silinder pillar model is shown in Fig. 2.

\subsection{Concrete Wing Curtain Model}

This study also used a concrete wing curtain placed in front of the bridge pillar model with a $40.0 \mathrm{~cm}$ height and curtain width of $3.0 \mathrm{~cm}$ and $5 \mathrm{~cm}$. The model was placed with variations in the distance between the pillars and the curtain, as shown in Fig. 3. Fig. 4 shows the other stages that were carried out.

The channel used is a soil channel overlaid with sand.

The channel used was a soil channel overlaid with sand material and a trapezoidal cross-section. The geometric shape of the channel was straight with permanent walls of channel bottom width (B), height $(\mathrm{H})$ and length (L) channel model is shown in Fig. 1.

\subsection{Pilar Model}



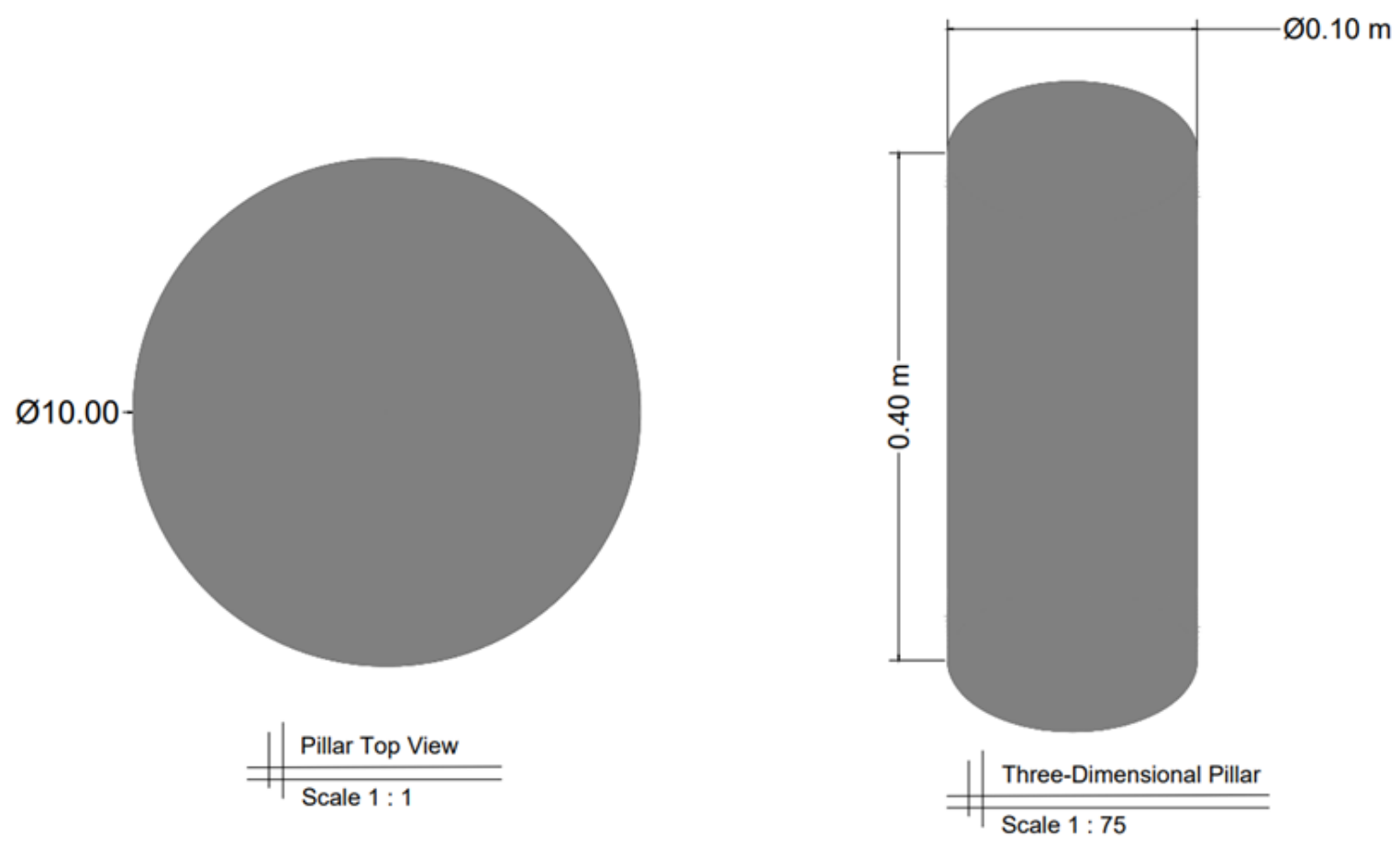

Figure 2. Silinder pillar model
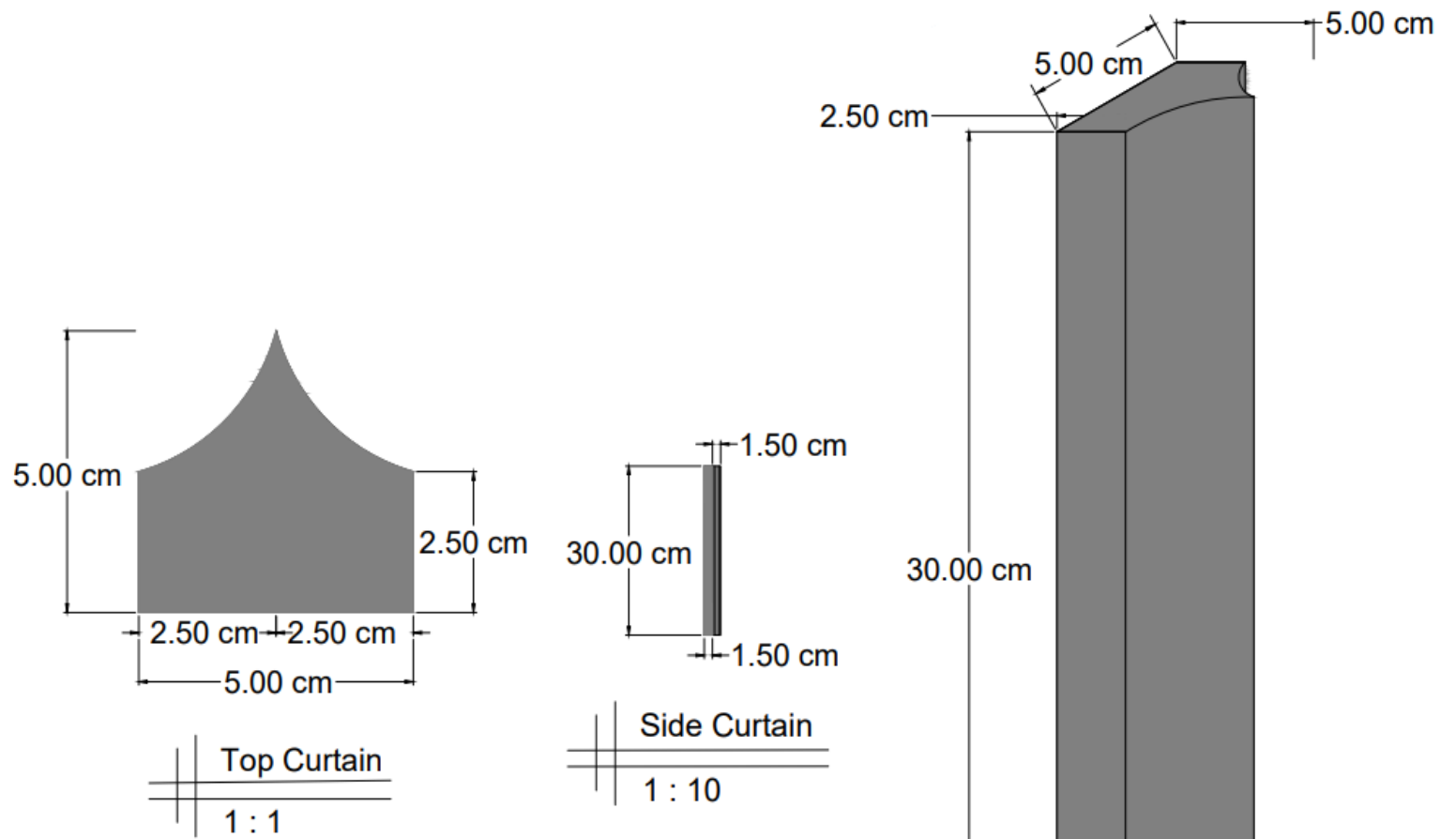

$30.00 \mathrm{~cm}$
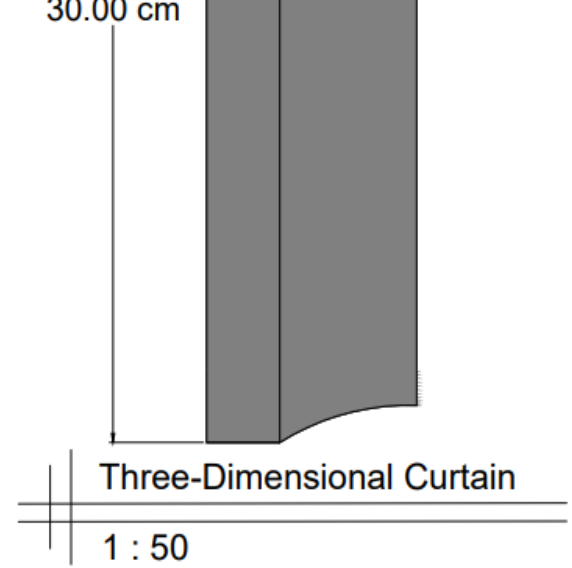

Figure 3. Concrete wing curtain models 


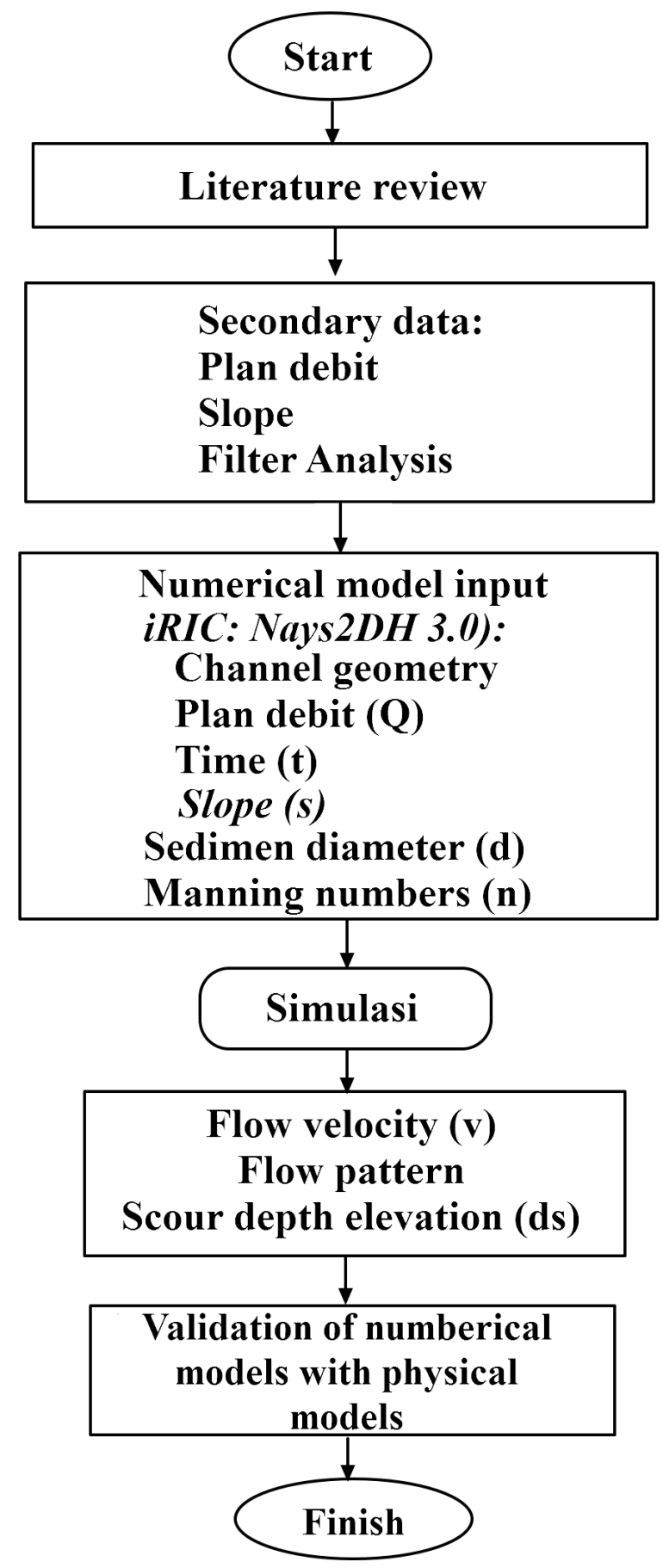

Figure 4. Study Flow Chart

\subsection{Data}

The iRIC software, Nays2HD 3.0. used data such as channel geometry, discharge, slope, the cross-section of pillars, and manning numbers. The study data was obtained from physical modeling carried out in the laboratory. Afterward, the simulation results were compared using the iRIC software, Nays2DH 3.0. and a physical model.
Table 1. Flow conditions in the simulation

\begin{tabular}{cc}
\hline Uraian & Data \\
\hline Debit $\left(\mathrm{m}^{3} / \mathrm{s}\right)$ & 0,0134 \\
\hline Running duration (minute) & 3 \\
\hline Channel length $(\mathrm{m})$ & 6 \\
\hline Channel width $(\mathrm{m})$ & 0,50 \\
\hline Channel slope $(\mathrm{s})$ & 0,0022 \\
\hline Manning numbers $(\mathrm{n})$ & 0,022 \\
\hline Base material diameter $(\mathrm{mm})$ & 0,955 \\
\hline
\end{tabular}


For the iRIC software, Nays2DH 3.0, the channel geometry was converted into a grid. In this study, the grid used was determined by trial and error, with its model software shown in Fig. 5.

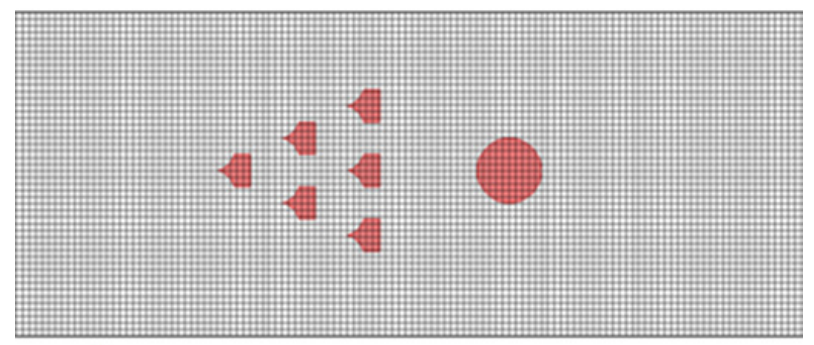

Figure 5. Grid model in iRIC: Nays2DH 3.0

\section{Results and Discussion}

\subsection{Discharge and Flow Velocity Rate Analysis}

This simulation used a discharge of $0.0134 \mathrm{~m} 3 / \mathrm{s}$ which was obtained from the discharge measuring table on the V-Notch Weir (table 2), while the flow velocity rate was based on the color scale (table 3 ).

Table 2. Flow analysis on the V-Notch Weir measuring instrument

\begin{tabular}{|c|c|c|c|}
\hline Waktu (t) & $\mathbf{C}_{\mathrm{d}}$ & $\mathbf{H}_{\mathrm{V} \text {-Notch Weir (m) }}$ & $\begin{array}{c}\mathbf{Q} \\
\mathbf{m}^{3} / \mathbf{s}\end{array}$ \\
\hline 15 & \multirow{3}{*}{0.599} & \multirow{3}{*}{0.155} & \multirow{3}{*}{0.0134} \\
\hline 40 & & & \\
\hline 60 & & & \\
\hline
\end{tabular}

Table 3. Flow velocity rate based on color scale without concrete wings

\begin{tabular}{ccc}
\hline No. & Color Scala & $\begin{array}{c}\text { Flow Velocity Rate } \\
(\mathbf{m} / \mathbf{s})\end{array}$ \\
\hline 1 & Dark blue & 0.000 \\
\hline 2 & Light blue & $0.143-0.285$ \\
\hline 3 & Green & $0.428-0.570$ \\
\hline 4 & Yellowish green & $0.570-0.713$ \\
\hline 5 & Reddish yellow & $0.713-0.855$ \\
\hline 6 & Red & 0.998 \\
\hline
\end{tabular}

Based on the simulation results using Nays2DH 3.0, the flow rate without a concrete wing curtain is illustrated by a color scale commencing from the lowest $0.000 \mathrm{~ms}-1$ in blue to the highest speed of $0.998 \mathrm{~ms}-1$ in red.

Figure 6 shows the difference in speed, illustrated in color. The rate commences from the lowest, $0.000 \mathrm{~ms}-1$ (in dark blue) to the highest, $0.998 \mathrm{~ms}-1$ (in dark red). Furthermore, the bridge pier velocity rate decelerates downstream at the end of the pier, which occurs within the upstream line of the channel.

Table 4. Flow velocity rate based on color scale using concrete wing curtain

\begin{tabular}{ccc}
\hline No. & Skala Warna & $\begin{array}{c}\text { Nilai kecepatan aliran } \\
(\mathbf{m} / \mathbf{s})\end{array}$ \\
\hline 1 & Dark blue & 0.000 \\
\hline 2 & Light blue & $0.121-0.243$ \\
\hline 3 & Green & $0.364-0.485$ \\
\hline 4 & Yellowish green & $0.485-0.606$ \\
\hline 5 & Reddish yellow & $0.606-0.728$ \\
\hline 6 & Red & 0.849 \\
\hline
\end{tabular}

The flow rate using a concrete wing curtain was illustrated on a color scale based on the simulation results using the iRIC software, Nays2DH 3.0. This scale commenced from the lowest $0.000 \mathrm{~ms}-1$ in dark blue to the highest speed of $0.849 \mathrm{~ms}-1$ in red as shown in Figure 7.

The flow velocity using a concrete wing curtain is lower than its velocity without using a concrete wing curtain. The initial flow velocity of the yellowish-green channel appeared upstream. Furthermore, the situation around the curtain became slow both upstream and downstream. Furthermore, acceleration also occurred on the right and left of the pillars and curtains towards the channel cliffs. Dominant changes in acceleration were shown by a yellow color, while the highest acceleration was reddish. The blue color showed a significantly low flow velocity rate around the pillar [7], [10].

\subsection{Flow Pattern}

The flow direction under normal conditions flows from upstream to the downstream channel. Based on the hydraulics theory, water will flow from high to low-pressure areas. However, provided that barriers such as bridge pillars and curtain buildings were at the middle of the channel, the flow direction turns. These barriers lead to flow turbulence which affects the depth and scour pattern.

The flow pattern simulation using the iRIC software, Nays2DH 3.0, can be illustrated through streamline. Subsequently, the flow pattern and curtain illustrated using this software as shown in the figure below. 


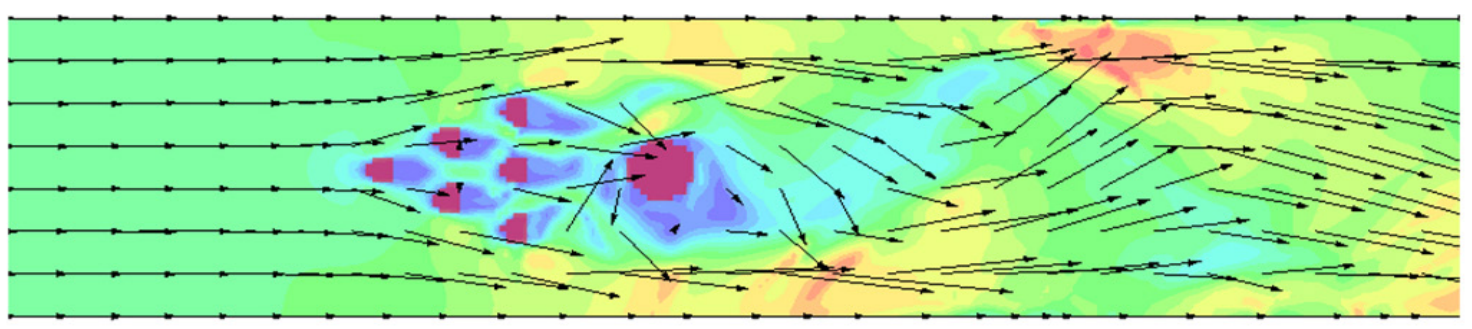

Velocity(ms-1) (magnitude)

$0.0000 .1430 .2850 .428 \quad 0.5700 .7130 .8550 .98$

Figure 6. Velocity and flow line without concrete wing curtain

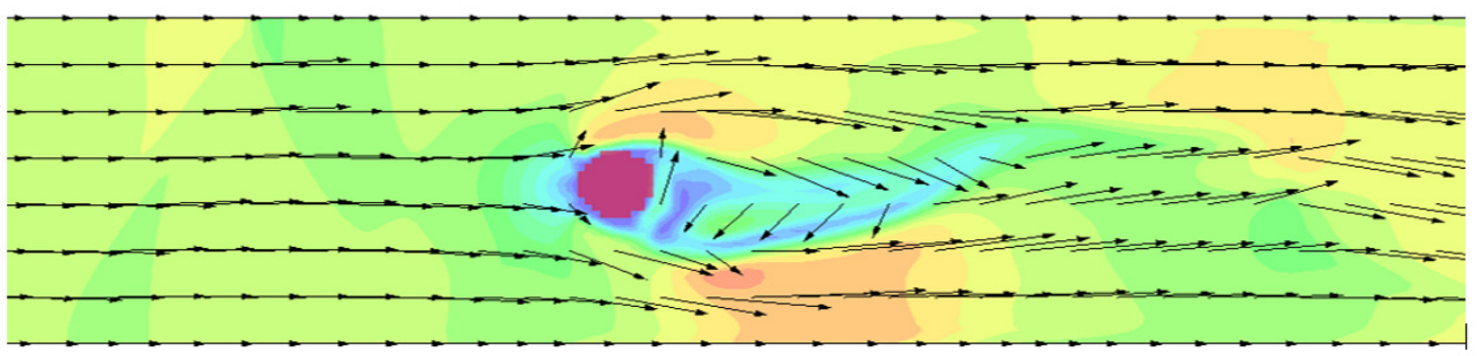

Velocity (ms-1) (magnitude)

$0.0000 .1210 .243 \quad 0.3640 .4850 .606 \quad 0.7280 .849$

Figure 7. Velocity and flow rate using concrete wing curtain

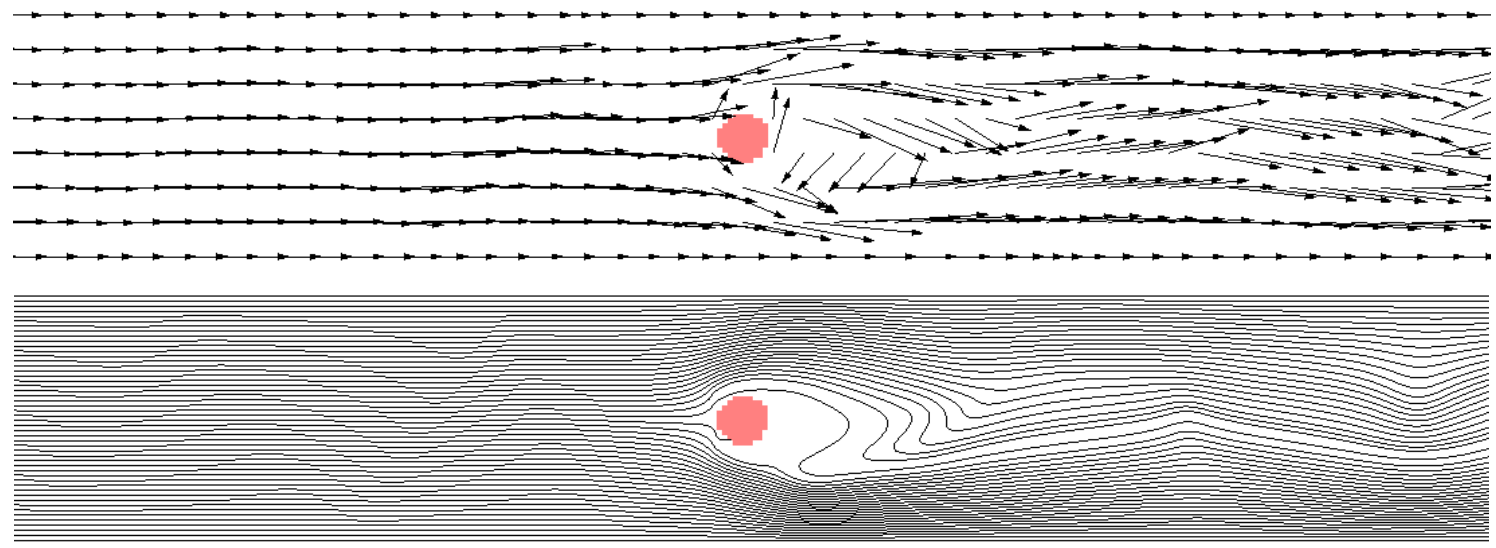

Figure 8. Flow pattern of bridge pillars without wing

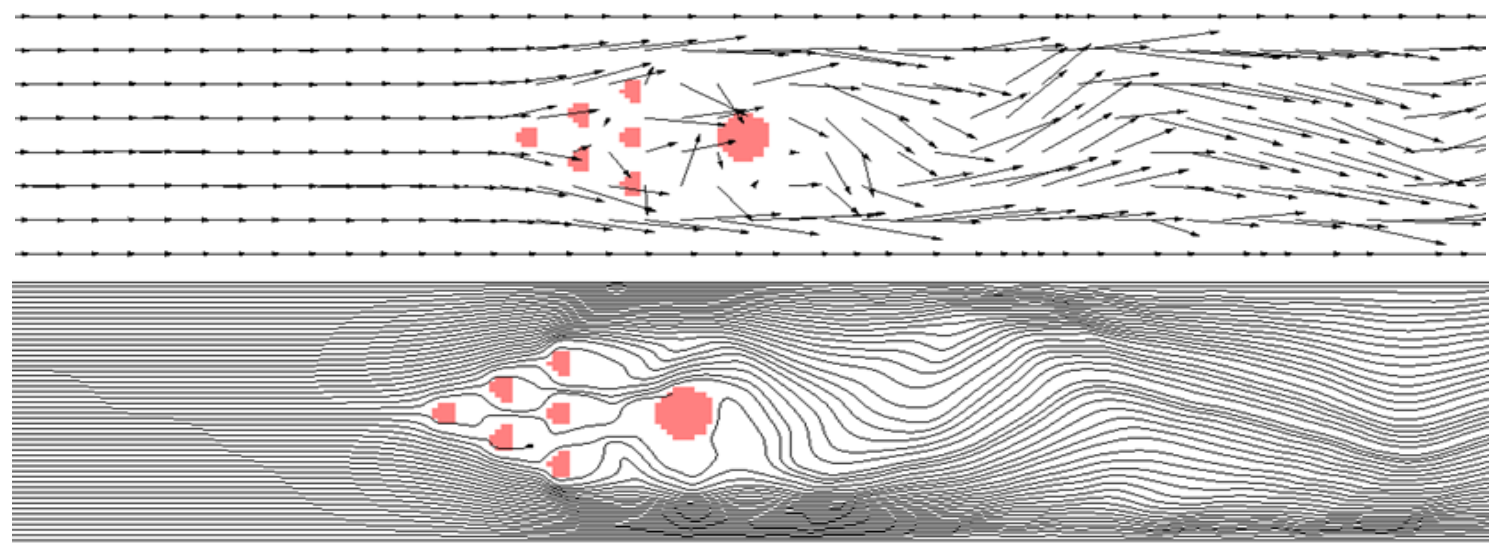

Figure 9. The result of flow pattern around bridge pillars and concrete wing curtain 
In Figure 8, the flow pattern and direction are altered after passing the bridge pillars which led to a vortex around the pillars. Meanwhile, Figure 9 shows that the flow pattern and direction were affected by the concrete wing opposite the bridge pillars, which reduced the vortex around the pillars. From upstream and downstream, it can be seen that there is turbulence on the right and left sides of the channel due to the concrete wing curtains which change the direction of flow. After passing through the pillar, the flow pattern slowly returned to normal.

It is assumed that the basic change of flow pattern around the pillars does not result in significant scouring. However, the base reaches equilibrium, especially on the right and left of the pillars where there is backflow velocity due to deceleration after passing through the curtain.

\subsection{Scouring Pattern}

The scour pattern around the bridge pillars occurs due to the flow being blocked by the pillars. This disrupts the flow pattern and leads to a vortex around the bridge pillars. The magnitude of the scour is determined by the vortex magnitude and the flow velocity around the bridge pillars. Furthermore, the simulation used the iRIC software, Nays2DH 3.0, to obtain the scour pattern with the channel base elevation as shown in Figure 10 below.
In this study, the change in the channel base elevation was influenced by the concrete wing curtain building in front of the bridge pillar which became a flow barrier. Figure 10 shows the base elevation indicated by a color scale. The red color shows the highest channel bottom elevation; meanwhile the blue color shows the lowest. The channel floor changed due to the presence of bridge pillars and concrete wings at the center of the channel.

The changes in elevation on the base channel have different characteristics provided that the concrete wings exist in front of the bridge pillars.

Figure 11 shows that the elevation around the pillars has only slight changes compared to those without the concrete wing curtain model, as shown in Figure 10. There is an elevation of the upstream bottom channel before the yellow concrete wing curtain has an identical color around the bridge pillars. This is because the presence of a curtain changes the direction of the flow velocity around the pillars, leading to a reduction and increase in the elevation of the channel base around the curtain. The elevation changes that occur on the right and left sides of the bridge pillars towards the canal wall in the form of reduction in the base elevation (scouring) can be seen from the green and light blue colors. Furthermore, there was an increase in the base elevation (sediment), as marked by a reddish color after the curtain and yellowish color after the downstream pillar.
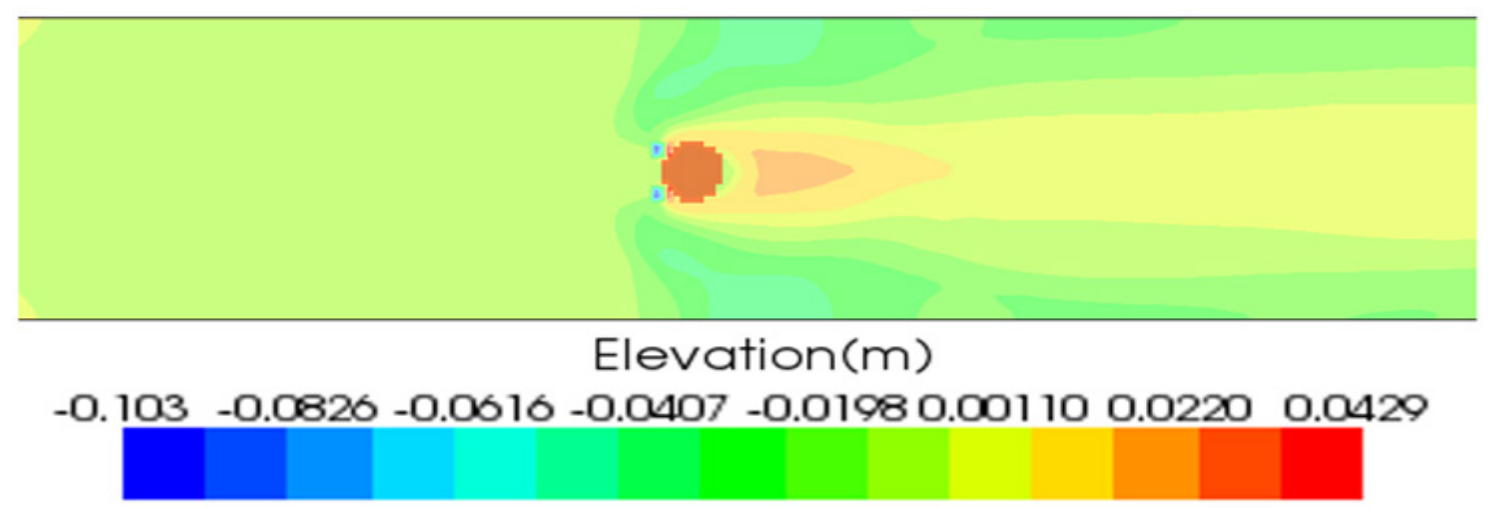

Figure 10. Base elevation on bridge pillars without curtains, concrete wings

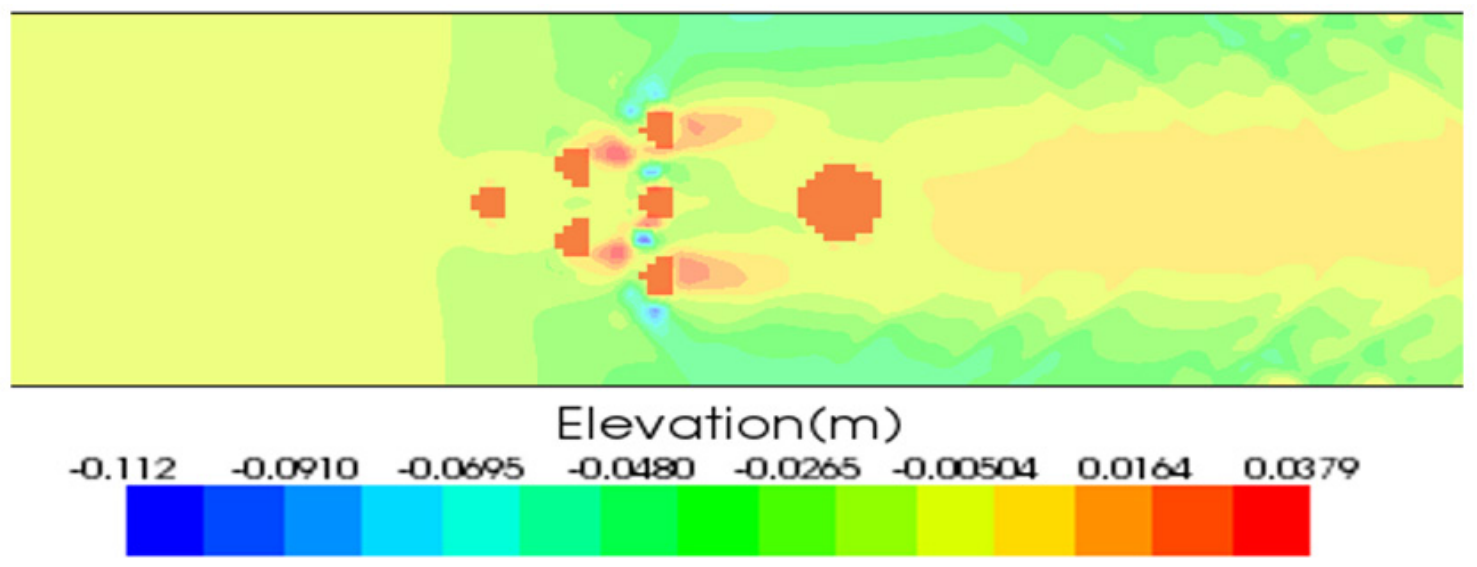

Figure 11. Base elevation on bridge pillars with concrete wing curtains 
Changes in the elevation of the base channel were not visible in the numerical model for the decrease or increase in elevation. Therefore, this study reviewed several sections around the bridge pillars. The review was carried out to obtain an in-depth analysis of the changes in the channel base elevation, particularly the analysis of scour around the bridge pillars. This was carried out in four sections as follows:

\subsubsection{Overview of sections I-I on the bridge pillars}

Sections I-I (Figure 12 and Figure 13) were cross-sections of the upstream girders on the grid $\mathrm{i}=341$ ( $0.45 \mathrm{~m}$ from the pillars). In this section, there was a scour on the right and left sides of the channel. Conversely, there was no change in elevation at the channel center. The biggest scour on the right side was at a distance of $0.01 \mathrm{~m}-0.03 \mathrm{~m}$ with a depth scouring (ds) of $0.0107 \mathrm{~m}$. The largest scour on the left side was at a distance of $0.045 \mathrm{~m}-0.50 \mathrm{~m}$ with a depth scouring (ds) of $0.0104 \mathrm{~m}$.

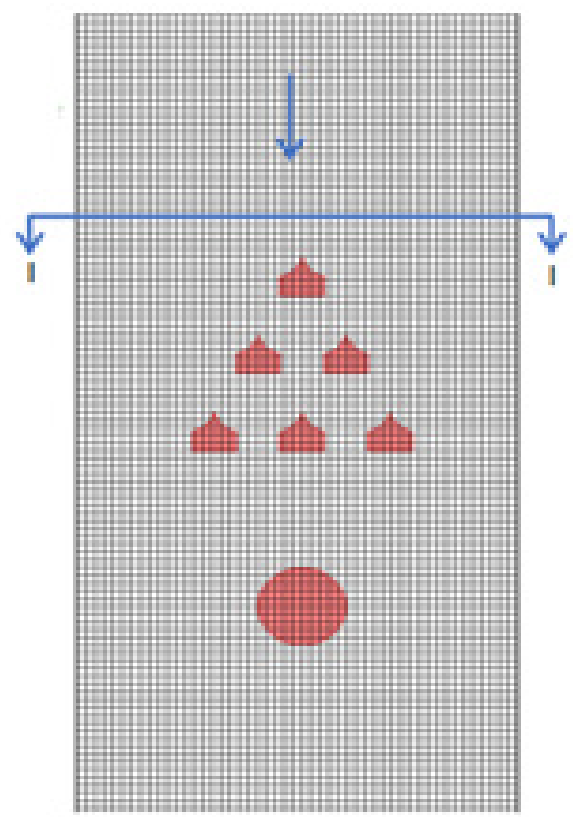

Figure 12. Section I-I Concrete wing curtains on the bridge pillars

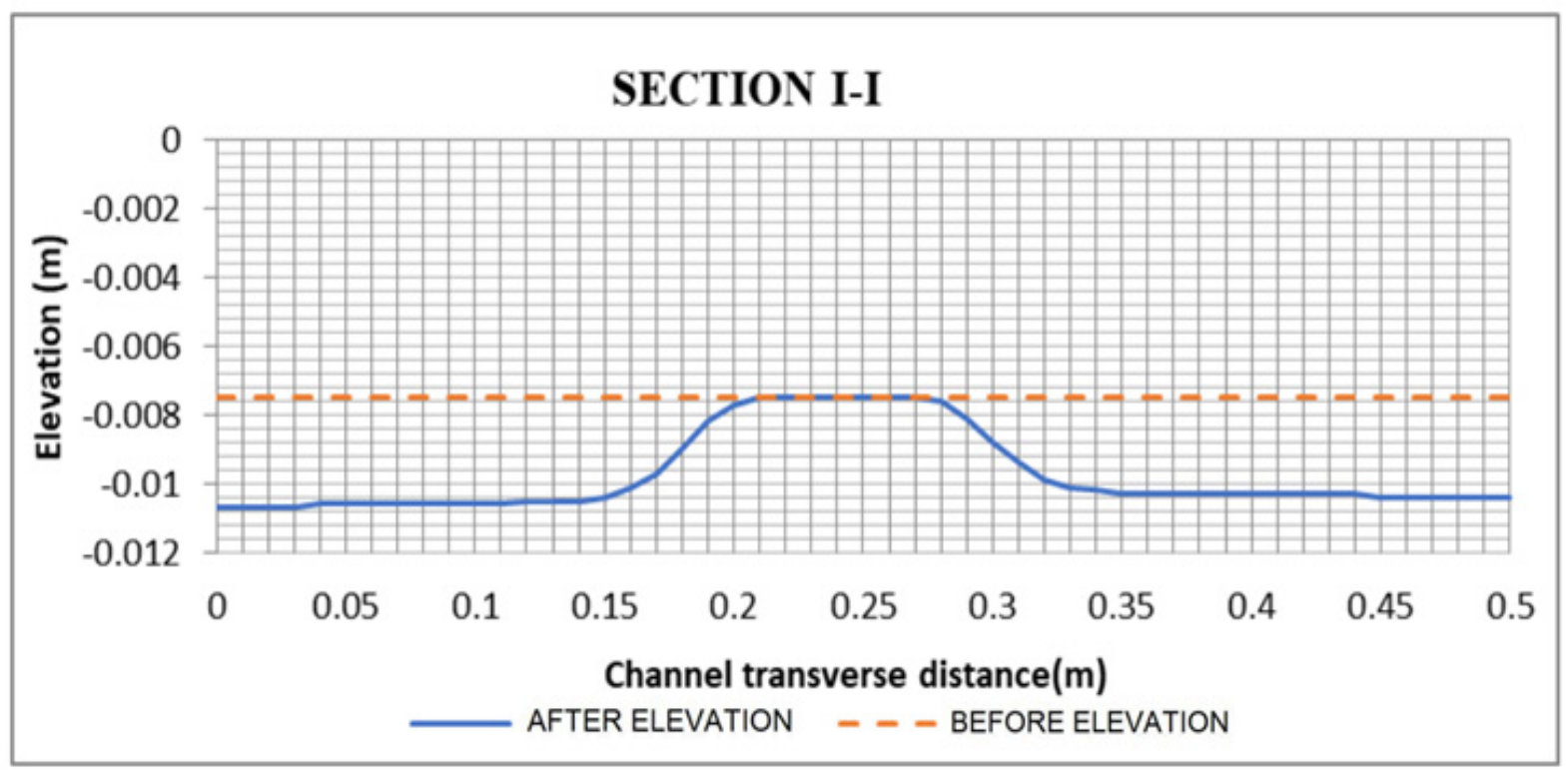

Figure 13. Elevation of the channel base on the I-I section of the concrete wing curtain on the bridge pillar 


\subsubsection{Overview of sections II-II in front of the bridge pillars}

Sections II-II (Figure 14 and Figure 15) were cross-sections of the upstream pillars on-grid $\mathrm{i}=381(0.05$ $\mathrm{m}$ from the pillars). In this section, there was scouring on the right and left sides of the channel. The biggest scour on the right side was at a distance of $0.01 \mathrm{~m}-0.02 \mathrm{~m}$ with a depth scouring $(\mathrm{ds})$ of $0.051 \mathrm{~m}$. The largest scour on the left side was at a distance of $0.049 \mathrm{~m}-0.50 \mathrm{~m}$ with a depth scouring (ds) of $0.054 \mathrm{~m}$. Besides experiencing a decrease in elevation, there was also a relatively small increase in the base elevation of the channel at a distance of $0.30 \mathrm{~m}-$ $0.035 \mathrm{~m}$ with a depth scouring (ds) of $0.001-0.004 \mathrm{~m}$. Furthermore, the channel center had a relatively small decrease in depth scouring at a distance of $0.022 \mathrm{~m}$ with a depth scouring (ds) of $0.013 \mathrm{~m}$.

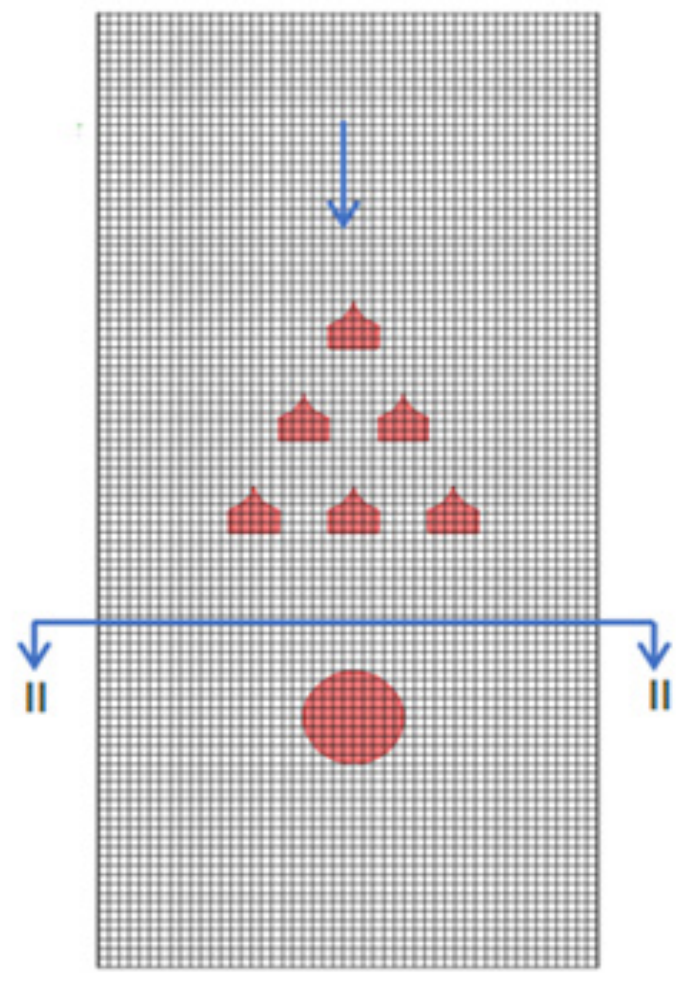

Figure 14. Section II-II Concrete wing curtains on bridge piers

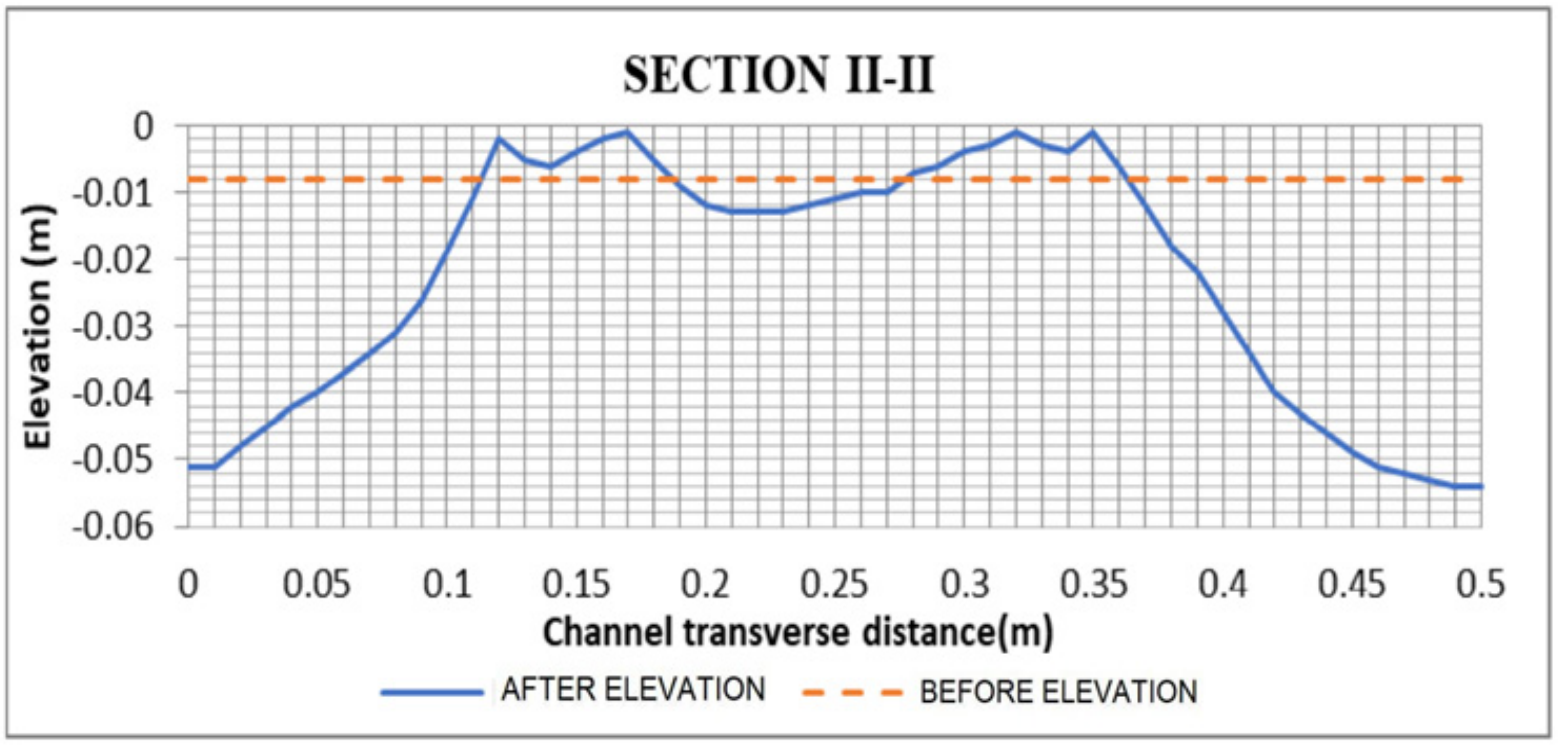

Figure 15. Channel floor elevation in sections II-II 
3.3.3. Overview of sections III-III in the middle of the bridge pillars

Sections III-III (Figure 16 and Figure 17) are cross-sections of the upstream pillars on-grid $\mathrm{i}=391$. In this section, there was scouring on the right and left sides of the channel. The biggest scour was on the left side at a distance of $0.048 \mathrm{~m}-0.50 \mathrm{~m}$ with a depth scouring (ds) of $-0.049 \mathrm{~m}$. In addition to experiencing a decrease in elevation, there is also a relatively small increase in bottom channel elevation, at a distance of $0.17 \mathrm{~m}-0.019 \mathrm{~m}$ at depth scouring (ds) of $-0.002 \mathrm{~m}$.

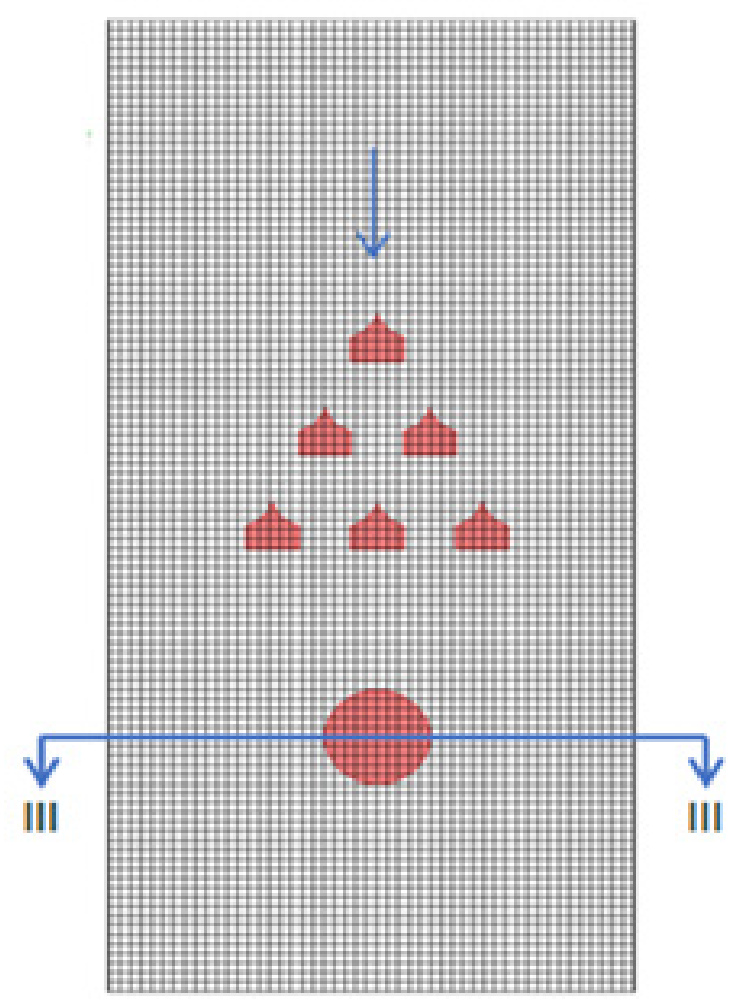

Figure 16. Sections III-III Concrete wing curtains on bridge piers

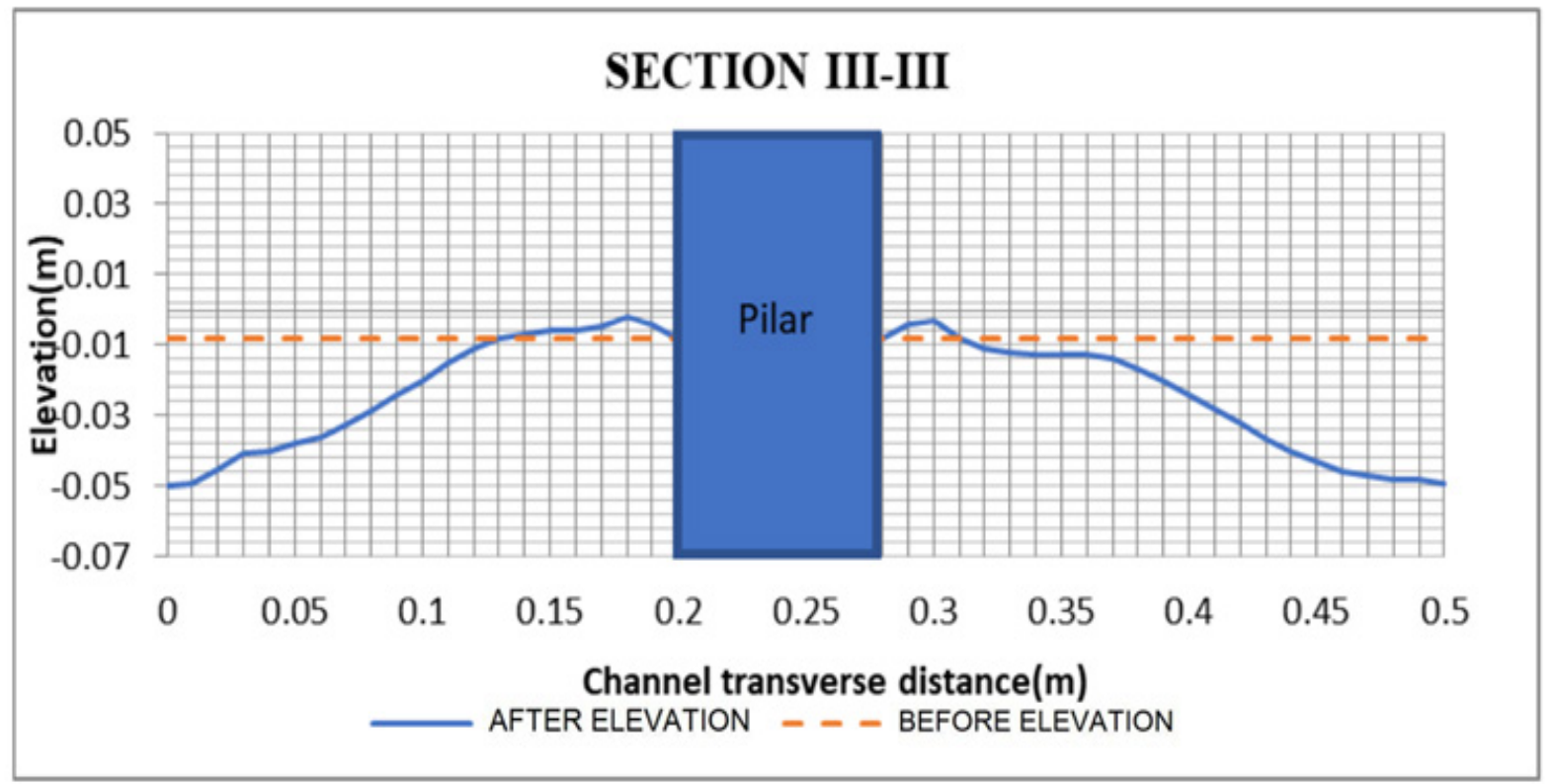

Figure 17. Channel floor elevation in sections III-III 


\subsubsection{Overview of IV-IV sections on the back of the pillar}

Sections IV-IV (Figure 18 and Figure 19) were cross-sections of the upstream pillars on-grid $i=401(0.05$ $\mathrm{m}$ after the pillars). In this section, there was scouring on the right and left sides of the channel. The biggest scour on the right side was at a distance of $0.01-0.03 \mathrm{~m}$ with depth scouring (ds) of $0.043-0.049 \mathrm{~m}$. The biggest scour on the left side was at a distance of $0.46-0.50 \mathrm{~m}$ with a depth scouring (ds) of $0.043-0.045 \mathrm{~m}$. Besides experiencing a decrease in elevation, there was also a relatively small increase in the channel bottom elevation a distance of $0.26 \mathrm{~m}$ with depth scouring (ds) of $-0.002 \mathrm{~m}$.

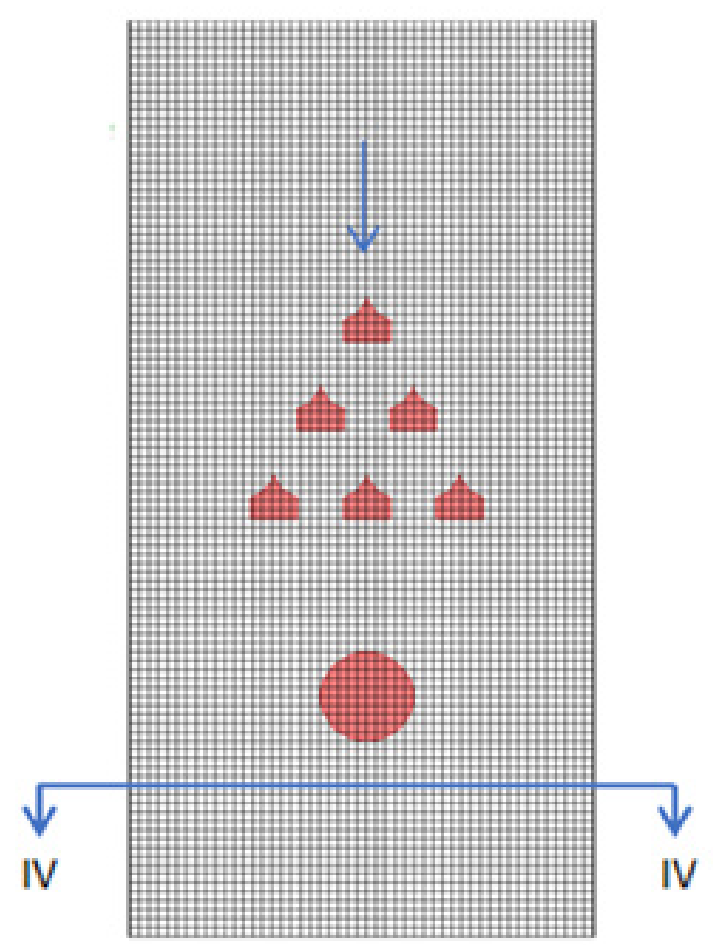

Figure 18. Sections IV-IV Concrete wing curtains on bridge piers

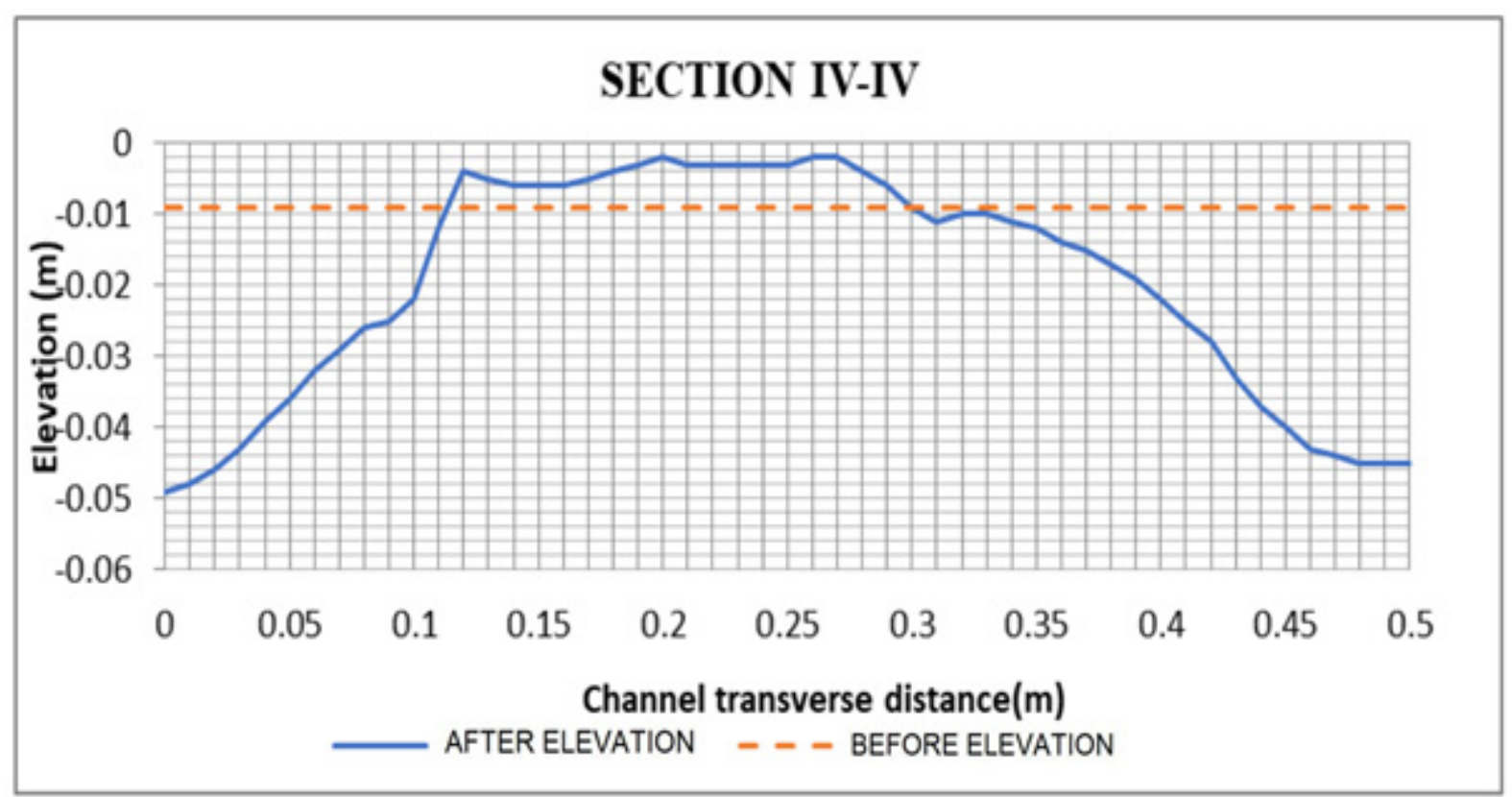

Figure 19. Elevation of the channel floor on section IV-IV 


\subsection{Analysis and Validation of iRIC Modeling}

The model validation was carried out by comparing the value of the iRIC Nays2DH 3.0 modeling results with the field measurement investigation. It was necessary to identify the model results with relative errors to meet further needs.

The validation analysis of the iRIC model that was reviewed was the flow velocity rate in the channel around the concrete wings and bridge pillars, as shown in Tables 5 and 6 below.

Table 5. Flow velocity validation analysis on iRIC modeling: Nays $2 \mathrm{DH}$ 3.0 with field measurements without a concrete wing curtain

\begin{tabular}{ccc}
\hline \multicolumn{2}{c}{ Flow Velocity (ms-1) } & $\begin{array}{c}\text { Rate } \\
\text { Erro (\%) }\end{array}$ \\
\cline { 1 - 2 } iRIC:Nays2DH3.0 & Field Measurement & 8.94 \\
0.451 & 0.540 & 5.42 \\
0.474 & 0.420 & 8.14 \\
0.461 & 0.380 & 13.34 \\
0.493 & 0.360 & 8.96
\end{tabular}

Table 6. Analysis of flow velocity validation on the RIC: Nays2DH 3.0 modeling with field measurements using a concrete wing curtain

\begin{tabular}{ccc}
\hline \multicolumn{2}{c}{ Flow Velocity (ms-1) } & \multirow{2}{*}{$\begin{array}{c}\text { Rate } \\
\text { Erro (\%) }\end{array}$} \\
\cline { 1 - 2 } iRIC:Nays $2 \boldsymbol{D H 3 . 0}$ & Field Measurement & \\
\hline 0.308 & 0.380 & 7.24 \\
0.349 & 0.340 & 0.88 \\
0.445 & 0.380 & 6.48 \\
0.358 & 0.320 & 3.84 \\
\hline Average & & 4.61 \\
\hline
\end{tabular}

The validation of the flow velocity between the iRIC model and the field measurements without curtains obtained an average rate of $8.96 \%$ for the channel without a concrete wing. Meanwhile, the average rate for the curtain model with the concrete wing was $4.61 \%$. This result indicated that the difference between the two models was relatively small. Furthermore, the flow velocity in the channel with the concrete wing was smaller than its velocity without the wing, due to the reduced channel cross-sectional area.

\section{Conclusions}

Based on the results of the analysis, it can be concluded that the output velocity (ms-1), which occurred around the bridge pillars and the concrete wing curtain was insignificant due to the change in flow direction after the curtain. Furthermore, the output arrow velocity (ms-1) had a flow pattern around the bridge pillars with concrete wing curtains that had a turbulence pattern. Therefore, the flow direction changes after passing through the concrete wing curtains and bridge pillars. At the output elevation (m), the scour that occurred around the pillars was insignificant due to the presence of concrete wing curtains in front of the pillars. Meanwhile, there was a significant scour on the left and right sides of the channel after the pillars. The results of the validation between the analysis of the iRIC model and the physical model output velocity (ms-1) had an insignificant difference of $4.61 \%$.

\section{Acknowledgments}

This study was supported by the Higher Education Directorate General of the Ministry of National Education, with a study grant from the Higher Education Applied Research.

\section{REFERENCES}

[1] Nenny, S. Pallu, A. Thaha, and F. Maricar, "THE INFLUENCES OF CONFIGURATION TO CURTAIN ON DEFORMATION ZONE PILLAR Keywords: configuration, pillars, curtains, agradasi, degradation," 2014, no. Isid.

[2] Nenny, M. S. Pallu, and M. A. T. dan Farouk Maricar, "Local scour analysis study to hexagonal pillar by Using Shape Curtain Rectangular With Wedge Shape Curve (RWWSC)," ARPN J. Eng. Appl. Sci., vol. 9, no. 10, pp. 1823-1827, 2014.

[3] Z. Bozkus and M. Çeşme, "Reduction of scouring depth by using inclined piers," Can. J. Civ. Eng., vol. 37, no. 12, pp. 1621-1630, 2010, doi: 10.1139/L10-099.

[4] S. Pagliara and I. Carnacina, "Influence of large woody debris on sediment scour at bridge piers," Int. J. Sediment Res., vol. 26, no. 2, pp. 121-136, 2011, doi: 10.1016/S1001-6279(11)60081-4.

[5] O. Link et al., "A model of bridge pier scour during flood waves," J. Hydraul. Res., vol. 55, no. 3, pp. 310-323, 2017 , doi: 10.1080/00221686.2016.1252802.

[6] O. LINK, F. PFLEGER, and U. ZANKE, "Characteristics of developing scour-holes at a sand-embedded cylinder," Int. J. Sediment Res., vol. 23, no. 3, pp. 258-266, 2008, doi: 10.1016/S1001-6279(08)60023-2.

[7] H. Al Imran and Nenny, "The effect of flow velocity on local scaling around hexagonal pillars (laboratory model test)," IOP Conf. Ser. Mater. Sci. Eng., vol. 403, no. 1, 2018, doi: 10.1088/1757-899X/403/1/012015.

[8] D. Picetti, S. Foster, A. Pangle, A. Schrader, J. Wei, and G. Azhar, "Full Length Research Article," Age (Omaha)., vol. 60, no. 69, p. 20.37, 2017.

[9] L. Brandimarte, P. Paron, and G. Di Baldassarre, "Bridge pier scour: A review of processes, measurements and estimates," Environ. Eng. Manag. J., vol. 11, no. 5, pp. 975-989, 2012, doi: 10.30638/eemj.2012.121.

[10] A. Mazumdar, "Local scour around hydraulic structures," no. October, p. 1263, 2016, doi: 10.1201/9781315644479199. 